\title{
A COVID-19 E OS IMPACTOS NO SISTEMA EDUCACIONAL DE PERNAMBUCO
}

\author{
Claudison Vieira de Albuquerque ${ }^{1}$ \\ António Manoel Rochette Cordeiro ${ }^{2}$ \\ Joaquim Luis Medeiros Alcoforado ${ }^{3}$ \\ João Allyson Ribeiro de Carvalho ${ }^{4}$
}

\begin{abstract}
RESUMO: O surgimento da primeira pandemia do século 2I, a COVID-19, provocou mudanças estruturais nas mais diversas áreas. Atingiu desde as questões ligadas às relações interpessoais, passando por fatores econômicos, sociais e sanitários. O sistema educacional de todo o planeta foi sem dúvidas um dos setores mais afetados. Porém, os países periféricos foram os que mais sentiram esses impactos. Urge buscar novos modelos que sejam capazes de atender de forma igualitária as demandas de toda sociedade, comprometido com uma política de inclusão, capaz de alcançar a todos e em todos os lugares.
\end{abstract}

Palavras chaves: Pandemia. Covid- 19. Sistema Educacional. Pernambuco.

ABSTRACT: The emergence of the first pandemic of the 2ist century, COVID-i9, caused structural changes in the most diverse areas. It has affected issues related to interpersonal relationships, including economic, social and health factors. The educational system across the planet was undoubtedly one of the sectors most affected. However, the peripheral countries were the ones that most felt these impacts. There is an urgent need to seek new models that are capable of meeting the demands of the whole society on an equal basis, committed to a policy of inclusion, capable of reaching everyone and everywhere.

Keywords: Pandemia. Covid- 19. Educational System. Pernambuco.

\footnotetext{
I Doutorando em Estudos Contemporâneos pelo Centro de Estudos Interdisciplinares do Século XX da Universidade de Coimbra. Mestre em Tecnologia Ambiental pelo Instituto Tecnológico de Pernambuco -ITEP e Graduado em Geografia pela Universidade de Pernambuco. Atualmente está Secretário de Educação do Município de Feira Nova- PE. Lattes: http://lattes.cnpq.br/8931663163707550. Orcid: https://orcid.org/oooo-oooz1887-42r. E-mail: claudisonalbuquerque@gmail.com.

2 Doutor em Geografia pela Universidade de Coimbra. É professor da Universidade de Coimbra no Departamento de Geografia, do Programa de Doutorado do Centro de Estudos Interdisciplinares e de Mestrado e Doutorado pelo Departamento de Arquitetura e Urbanismo da Universidade de Coimbra. Orcid: https://orcid.org/oooo-ooo2-8648-3204. Lattes: http://lattes.cnpq.br/7823977679438842. E-mail: rochettecordeiro@fl.uc.pt.

3 Doutor em Ciências da Educação pela Universidade de Coimbra. É Professor na Faculdade de Psicologia e de Ciências da Educação da Universidade de Coimbra, do Programa de Doutorado do Centro de Estudos Interdisciplinares e de Ciências da Educação da Universidade de Coimbra. Lattes: http://lattes.cnpq.br/8528377297670214. Orcid: https://orcid.org/oooo-0oo3-4425-70Ir. E-mail: lalcoforado@fpce.uc.pt.

${ }^{4}$ Licenciatura em Geografia pela Universidade de Pernambuco. Mestrado em Geociências pela Universidade Federal de Pernambuco e Doutorado em Geociências pela Universidade Federal de Pernambuco. Atualmente é professor adjunto da Universidade de Pernambuco e integrante do núcleo docente estruturante da Universidade de Pernambuco. Lattes: http://lattes.cnpq.br/8096236027203954 Orcid: https://orcid.org/oooo-ooo3-4771-0491 Email: allyson.carvalho@upe.br
} 


\section{INTRODUÇÃO}

$\mathrm{O}$ ano de 2020 ficará marcado nos anais da história como um dos anos mais emblemáticos do início do século 2I. É verdade que não pode ser desconsiderado como marcante o famoso II de setembro de 20oI, desencadeando logo após a primeira guerra deste século envolvendo os Estados Unidos e o Afeganistão, em nome do “combate ao terrorismo". Também não pode deixar de se registrar a crise de 2008, quando nos Estados Unidos da América, iniciou-se uma crise econômica com efeitos globais, em detrimento da bolha do mercado imobiliário, exigindo uma intervenção do Estado e expondo as primeiras deficiências do neoliberalismo.

Porém, em nada esses eventos se aproximam com o que ocorre em 2020/2021. O surgimento em dezembro de 2019, na cidade de Wuhan, capital da província da China Central, de um vírus denominado de CORONAVÍRUS, colocou todo o planeta em alerta. Após a decretação de pandemia pela Organização Mundial da Saúde, as ações implementadas em praticamente todos os países, resultaram na maior operação sanitária, financeira e social da história do capitalismo, superando inclusive os aportes para a reconstrução da Europa e demais países no período pós guerra.

Os impactos dessas ações afetaram praticamente todos os setores da economia, excetuando apenas os da área da saúde e afins, setor responsável pelo enfrentamento direto a pandemia. A maioria dos segmentos teve perdas consideráveis. O setor educacional foi sem dúvida um dos mais atingido no que se refere às paralisações e respostas ao enfrentamento da crise.

\section{METODOLOGIA}

Este trabalho se baseou na análise de documentos norteadores oficiais e institucionais, a saber: Currículos Escolares, Bases Comuns Curriculares, Relatórios da Organização Mundial da Saúde e Protocolos Sanitários e Pedagógicos da UNDIME, CONSED, Ministério Público de Pernambuco, Ministério da Educação do Brasil e Secretaria de Educação do Estado de Pernambuco. Foram utilizados também artigos publicados e disponibilizados nas principais plataformas de busca. $\mathrm{O}$ tratamento metodológico é estritamente qualitativo e se deu pautado no que orienta 
Minayo (2008), adotando os seguintes passos: Preparação das informações; Transformação do conteúdo em unidades; Categorização; Descrição e Interpretação.

\section{HISTÓRIA DAS PANDEMIAS}

A humanidade vivencia neste momento um novo episódio de pandemia, termo utilizado para caracterizar uma epidemia que toma proporções planetária, a COVID-ı, uma das sete formas de manifestação do coronavírus em seres humanos. Tema que será tratado de maneira mais aprofundada posteriormente. Mas, não é a primeira vez que o planeta passa por um episódio de pandemia. Nos próximos parágrafos serão discorridos um pouco sobre os principais surtos pandêmicos no mundo.

Desde os primórdios da humanidade que existem referências de casos de epidemias ou pandemias. Na história dos hebreus, relata a Bíblia, que enquanto Moisés buscava negociar com o Faraó a liberdade de seu povo, algo refutado por ele, ocorreram alguns episódios epidemiológicos. A Bíblia relata ainda o que para alguns autores é considerado o primeiro episódio registrado na história sobre a peste bubônica, quando da tomada da Arca do Senhor pelos filisteus, conforme pode ser observado no trecho de Io Samuel, cap.6, vers. 9 "A mão do Senhor veio contra aquela cidade, com uma grande vexação; pois feriu aos homens daquela cidade, desde o pequeno até ao grande e tinham hemorroidas nas partes secretas". (BIBLÍA SAGRADA, 199I).

De forma mais sistemática, o primeiro relato que trata da Peste Bubônica ou Peste Negra, como ficou conhecida popularmente, por apresentar manchas escuras na pele, e que tomou proporções de pandemia, ocorreu no meado do século XIV. Suspeita-se que ela tenha surgido na Cidade de Veneza, Itália, porém, há outras fontes que dizem ter surgido na Ásia Central. Por serem cidades portuárias e centro de dispersão de pessoas e mercadorias, a doença se espalhou facilmente e atingiu diversos países do próprio continente e pelo menos dois outros continentes, a Ásia e a África.

Não há números precisos, mas a doença pode ter dizimado aproximadamente I/3 da população europeia, número que pode ter variado entre 75 e roo milhões de 
pessoas. Essa pandemia se alastrou e matou também uma parte considerável da população do continente africano e asiático. Dados dão conta de que um número próximo de 24 milhões de pessoas morreram nos países do Oriente (Lopes, op. cit, p. 172). A epidemia medieval, como também pode ser chamada, foi causada por uma bactéria, a Yersinia Pestis, transmitida por meio de pulgas, tendo como principal hospedeiro os roedores.

Por falta de protocolos de higienização e desconhecimento da origem e do vetor de transmissão, a doença causava pânico na população, pois pensavam ser transmitidas de uma pessoa infectada para outra através da respiração. Segundo Bittencourt (2020), a curva de descendência dessa doença só começou a decair, quando as cidades começaram a adotar medidas sanitárias mais eficazes e implementar sistemas de saneamento básico, fato ocorrido somente a partir do século XIX. Reforça ainda o autor, que o isolamento social acabou contribuindo para amortização dos casos.

Outra doença que se tornou pandêmica foi o surto de cólera. Ela é provocada pela bactéria Vibrio cholerae. Surgida em 1817 , matou dezenas de milhões de pessoas desde então. Sua contaminação ocorre através da ingestão de água e ou alimentos contaminados. Essa bactéria sofre bastante mutação, por isso, seu ciclo ocorre com certa frequência. Isso se constata quando se percebe que ela surgiu em 1817, mas, voltou a acontecer em 1832, na Europa, Canadá e Inglaterra; em I852 na Rússia; entre I863 e 1875 voltou a atacar a Europa e África; I866 mais uma vez na América do Norte; I899 ocorre de novo na Rússia e em 196i na Indonésia, Bangladesh e União Soviética, (NEWS@FMLU,2020).

A ausência de saneamento básico é um fator determinante para a proliferação da doença e surgimento de novos ciclos. Por essas razões, é mais comum encontrar essa pandemia em países subdesenvolvidos. A Europa e a América Anglosaxônica não relatam casos há algumas décadas. Por outro lado, países da África e América Central, sofrem ciclicamente com a cólera.

Em 2oro, o Haiti, um dos países com menor IDH do planeta, logo depois de ser atingido por um terremoto de 9 graus na escala Richter, que causou a morte de mais de 250 mil pessoas, viu o número de casos se alastrarem por todo o seu 
território. Outra nação que recentemente sofreu com a doença, foi o Iêmen, tendo registrado mais de 40 mil mortes em 2019, em decorrência do surto, (REVISTA GALILEU, 2020).

Também há de se registrar o surto da gripe espanhola como outra doença que foi considerada pandemia pelas autoridades sanitárias. Diagnosticada pela primeira vez em 1918, perdurou até 1920. Essa doença recebeu esse nome por ter sido a Espanha um dos territórios mais atingidos e por não se recusar a falar abertamente sobre a doença. Outros países na Europa e também fora dela foram duramente afetados. Os casos foram registrados na América do Norte (em especial nos Estados Unidos da América) Central e do Sul, no Sudeste Asiático, no Japão e na China.

Estima-se que o saldo de mortos tenha sido algo entre 20 e 40 milhões de pessoas e 500 milhões foram infectadas, ou seja, um quarto da população mundial da época, (FIOCRUZ, 2020).

Por ter ocorrido logo após o fim da Primeira Guerra Mundial, os impactos dessa pandemia em todos os aspectos possíveis (sanitários, sociais, econômicos) foram devastadores. A Europa que já estava desolada e precisando se reconstruir precisou enfrentar mais um inimigo.

Dando continuidade as doenças que são consideradas pandemias pelos órgãos sanitários, aborda-se a partir de agora a COVID-i9. O surgimento em dezembro de 2019, na cidade de Wuhan, capital da província da China Central, de um vírus denominado de coronavírus, colocou todo o planeta em alerta. Após a decretação da pandemia pela Organização Mundial de Saúde, em II março de 2020, vários países no mundo adotaram medidas sanitárias, econômicas e restritivas para conter o surto.

O isolamento social e o uso de máscaras foram às medidas sanitárias mais adotadas entre os países. Em alguns casos mais extremos, foi necessário implementar o lockdown (fechamento total dos setores considerados não essenciais ao enfrentamento a pandemia). Conforme dados da OMS e do Imperial College de Londres, os países que conseguiram manter o isolamento social próximo dos $70 \%$, por um período de 15 a 2I dias, conseguiram evitar a morte de algo em torno de 120 mil pessoas no continente europeu. Já os países que não adotaram ou demoraram em 
adotar essas medidas, viram a curva de contágios e de mortos crescerem abruptamente, a exemplo do Brasil e dos Estados Unidos.

Após o surgimento na China, epicentro da doença entre dezembro de $2019 \mathrm{e}$ fevereiro de 2020, o vírus se espalhou rapidamente pela Europa, atingindo de maneira avassaladora países como a Itália, Espanha, França e Reino Unido. O número de mortes no continente é de algo em torno de I.005.00o milhões de pessoas, enquanto os de infectados ultrapassam a casa dos 37.665.00o milhões de habitantes (OMS, $22 / 03 / 2021)$.

Outros países da Europa e demais continentes foram fortemente atingidos pela doença, conforme pode ser observado na tabela a seguir com os dez países mais afetados no planeta.

Tabela I - Ralação dos dez países mais afetados pela COVID-ı9 no mundo.

\begin{tabular}{|l|l|l|}
\hline Local & Casos Confirmados & Mortes \\
\hline Global & $\mathbf{1 2 3 . 2 8 7 . 4 1 7}$ & 2.716 .696 \\
\hline $\begin{array}{l}\text { Estados Unidos da } \\
\text { América }\end{array}$ & 29.842 .972 & 541.937 \\
\hline Brasil & 11.998 .233 & 295.332 \\
\hline Índia & 11.646 .081 & 160.000 \\
\hline Rússia & 4.407 .031 & 93.457 \\
\hline Reino Unido & 4.296 .583 & 126.155 \\
\hline França & 4.282 .603 & 92.035 \\
\hline Itália & 3.212 .376 & 104.942 \\
\hline Espanha & 3.212 .332 & 72.910 \\
\hline Turquia & 3.013 .568 & 30.061 \\
\hline Alemanha & 2.670 .769 & 74.756 \\
\hline Colômbia & 2.337 .230 & 62.028 \\
\hline
\end{tabular}

Fonte: (OMS, 22/03/2021).

Além dos surtos pandêmicos antes descritos, podem ser citadas outras pandemias que afetaram de maneira considerável o planeta durante a história da 
humanidade e que dizimaram um número expressivo de pessoas. Conforme pode ser observado na tabela a seguir.

Tabela 2: Pandemias no decorrer da história da humanidade

\begin{tabular}{|l|l|l|}
\hline Pandemia & Ano & No de Mortos \\
\hline Peste de Atenas & 430 a.C & $*$ \\
\hline Peste de Cipriano & 250 a.C & $*$ \\
\hline Peste de Galeno & I60 a.C & $*$ \\
\hline Praga de Justiniano & 54I d.C & De 25 a 50 milhões \\
\hline Doença de Hansen ou Lepra & Século IX & 3 milhões \\
\hline Peste de Londres & I665 & 75 a roo mil \\
\hline Sarampo & I875 & 400 mil \\
\hline Gripe Russa & I889 & 500 mil \\
\hline Gripe Asiática & 1957 & I,I milhão \\
\hline AIDS & 198I & 35 milhões \\
\hline Gripe Suína & 2009 & 203 mil \\
\hline
\end{tabular}

Fonte: Faculdade de Medicina de Lisboa, 2020. *sem registros em números absolutos

\section{A COVID-ıg E A SUSPENSÃO DAS AULAS EM PERNAMBUCO}

Após a China informar a OMS uma nova doença surgida em Wuhan e com potencial de se tornar epidemiológica, vários países no mundo, incluindo o Brasil, começaram a adotar medidas que pudessem impedir ou mitigar os impactos em seu território.

Para isso, o governo brasileiro publicou a portaria de $\mathrm{n}$ - 188 de 03 de fevereiro de 2020, decretando Estado de Emergência. Esse decreto objetivava dá mais celeridade as medidas preventivas no país no que se referia ao combate ao coronavírus, mesmo não havendo nenhum registro do caso no Brasil. No dia 18 de março de 2020, através do decreto legislativo $\mathrm{n}^{\mathrm{o}}$ o6, o governo compreende a 
necessidade de declarar estado de calamidade pública, em decorrência do registro dos primeiros casos de coronavírus em território brasileiro, fato ocorrido na Cidade de São Paulo.

A partir do decreto nacional, o Estado de Pernambuco em 20 de março de 2020, publicou o decreto de número 48.834, cujo teor tratava das medidas de enfrentamento a COVID-19. Nele constavam as medidas de suspensão de todos os serviços considerados não essenciais e cuja suspensão contribuiria para a redução de aglomerações, fortalecendo o isolamento social, meio considerado pela OMS como uma das ações mais eficazes no combate a proliferação do vírus.

Por causa do modelo do pacto federativo do Brasil, as portarias ou decretos que tratavam da suspensão das aulas, ficaram por conta dos governos dos estados federados, exceto a do ensino superior ou técnico, cuja competência é do Ministério da Educação do Brasil. Com o registro do primeiro caso de transmissão comunitária do vírus no Estado, fato ocorrido em I6 de março de 2020, o governo sancionou o decreto de no 48.81o, da mesma data, que tratava especificamente da suspensão das aulas em todo o Estado, incluindo as redes públicas estaduais e municipais, privadas e filantrópicas, a partir do dia 18 de março de 2020.

\section{I - Políticas Públicas de Educação em Resposta a Pandemia}

As ações a partir de então no que se refere à suspensão das aulas foram ocorrendo de forma escalonada. A primeira medida adotada foi à antecipação das férias escolares, que ocorrem no mês de julho, sendo vivenciada entre 18 de março e I7 de abril para as redes privadas e entre 18 e 31 de março para as redes públicas (as férias dos alunos da rede pública no Brasil ocorrem em janeiro, sendo concedido em julho um recesso escolar de is dias). Nesse intervalo, as equipes gestoras, técnicas e pedagógicas das secretarias de educação traçaram os planos que seriam adotados enquanto oferta de ensino remoto aos alunos.

A segunda ação tratava da implementação dos sistemas de apoio as aulas remotas. Para isso, vários projetos foram desenhados e cenários foram sendo construídos. O uso das plataformas digitais disponíveis na rede mundial de computadores, como por exemplo, o uso de videoconferência usando o Google Meet, 
Zoom, Jitsi Meet, WhatsApp; os recursos básicos Google (Gmail, Google Drive, Formulários Google, Google Keep); o Pacote Office (Introdução a Apresentações via PowerPoint); as ferramentas para gravação de tela (Loom); os programas para produções e edições de Vídeo (Inshot, Quik Story e Shotcut); o uso das redes sociais como o WhatsApp, Facebook e Instagram para os ambientes virtuais de aprendizagem (AVA); as atividades remotas (Escola Games, Khan Academy, outros); os jogos educativos (Educaplay, FazGame, Kahoot); a gamificação (Classcroft); os vídeos interativos (Playposit); as avaliação online (Google Forms + Timmify); as atividades interativas (Socrative, Padlet, Stripgenerator), entre outras possibilidades, foram disponibilizadas para que os professores a utilizassem como meio de alcançar os seus alunos e manter a oferta das aulas durante a pandemia.

Foi adotada ainda como ação, a construção de apostilas que eram impressas nas escolas e que podiam ser retiradas no setor pedagógico das escolas ou quando impossibilitada essa ação, encaminhava-se as residências dos alunos. Essa ação poderia ser realizada para todas as turmas e modalidades, mas era focada principalmente nas turmas da Educação Infantil e Anos Iniciais do Ensino Fundamental, uma vez que o manejo dessa faixa etária com a tecnologia ainda não é completo, além de não ser recomendado o uso por muito tempo desses equipamentos pelos especialistas da área da saúde.

Por fim, também foi adotado um programa de complementação nutricional para os alunos que compõem a lista do CADÚNICO - cadastro do Ministério da Cidadania do Brasil, que reúne a população de baixa renda, aqueles cujo coeficiente salarial é de $\mathrm{I} / 4$ do salário mínimo por cada membro da família. Através desse cadastro, monitoram-se os alunos que por razões diversas, se encontram em situações de vulnerabilidade social ou iminente vulnerabilidade. Esse programa consiste em disponibilizar um cartão magnético com um valor pré-fixado, para que os pais/responsável adquiram alimentos em estabelecimentos comerciais previamente cadastrados.

Assim como relatado na maioria dos países, as dificuldades enfrentadas para a oferta dessas aulas foram inúmeras. A seguir pontuam-se alguns entraves que 
comprometem a execução das aulas e que também tem sido reportada na realidade da educação no Estado de Pernambuco.

I - As brechas digitais - Como ocorrido em praticamente todos os países do planeta, as redes de ensino foram pegas de surpresas e não conseguiram apresentar respostas a altura para resolver ou até mesmo atenuar as perdas advindas desta pandemia. Porém, segundo uma pesquisa da Universidade Autônoma do México, envolvendo oito países da América Latina, esse problema se apresentou ainda maior, uma vez que as chamadas "brechas digitais", termo usado para explicar à ausência/acesso de alunos aos produtos ligados a tecnologia (computador, tabletes, notebooks, smartphones, internet, etc.), são muito maiores do que em países de outros continentes, em especial da América do Norte, Europa e Ásia. Conforme pesquisa da La Unión Internacional de Telecomunicaciones (UIT, 2017), o Brasil se coloca atrás do Uruguai, Argentina, Chile e Costa Rica ficando a frente apenas da Colômbia, Venezuela e do México.

A pesquisa demonstra que na proporção que essa análise vai utilizando filtros, esse abismo tende a piorar. As universidades e redes de ensino particulares, por atenderem alunos na sua maioria de classe média alta ou rica, afirmam que as atividades remotas estão alcançando uma parcela significativa dos seus alunos. Afirma ainda que o feedback é satisfatório e que apesar das dificuldades, acreditam que o ano/semestre letivo não está totalmente comprometido. $\mathrm{Na}$ contramão disso, na maioria das universidades e escolas da rede de ensino pública do país, em especial em alguns estados do Norte Nordeste do Brasil, essas brechas digitais são gigantescas. Sendo assim, a perda do ano letivo é praticamente certa.

Segundo informações que constam no site da Secretaria de Educação do Estado de Pernambuco, corroborado pela União Nacional dos Dirigentes Municipais de Educação, secção Pernambuco - UNDIME-PE, praticamente I/3 dos municípios do estado não tinham conseguido implementar até junho de 2020 as aulas remotas em sua rede. Para justificar a ação, alegam que aproximadamente 60\% dos seus alunos residem em áreas rurais, cujo acesso a rede de dados móveis ou internet banda larga via wi-fi é limitada ou inexistente. Os residentes das áreas urbanas, mas que residem nas periferias e bairros pobres, também relatam dificuldades em acessar as 
plataformas e assistirem as aulas. Esse número não diverge muito do obtido pela UAM, quando afirma que $2 / 3$ dos alunos dos países pesquisados afirmam as mesmas proposições, (INEGI, 20I8a).

2- A Falta de acesso e aproveitamento as mídias e as tecnologias já existentes - os problemas ora citados, poderiam ser mitigados, caso as lideranças governamentais e demais instituições, inclusive as empresariais, disponibilizassem os meios já existentes, ainda que em certos casos precarizados, para darem suporte às redes de ensino e levarem aos alunos a terem acesso às aulas.

Ainda segundo a UAM, na maioria dos países pesquisados em média apenas uma operadora de telefonia disponibilizou suas torres de transmissão de dados e passou a não cobrar do pacote de serviços os dados móveis que fossem usados nas redes sociais ( WhatsApp, Facebook, Instagran, etc.) e praticamente nenhuma rede de televisão privada dispôs sua estrutura para que os alunos acessassem as plataformas e assistissem as aulas.

No caso específico de Pernambuco, houve a utilização da TV da Assembleia Legislativa e TV Universitária, mas a área de alcance de suas torres de transmissão se limita a Região Metropolitana do Recife e Zona da Mata de Pernambuco, não abrangendo a totalidade do território do Estado. Relatam os técnicos da Secretaria de Educação que a mensuração do alcance destes mecanismos também é um complicador.

3. Formação profissional digital deficitária - outro aspecto abordado está ligado à dívida que os países latinos americano têm com a formação de seus professores. Segundo a pesquisa da UAM, nesse contexto não está sofrendo apenas os alunos, boa parte dos professores, quiçá, a maioria, não estava preparado para lidar com uma mudança metodológica abrupta, como ocorrido nesse cenário de pandemia. Quando somada a inabilidade do professor no que se refere ao domínio das tecnologias, com a ausência dos meios, os resultados são catastróficos. Essa dívida faz com que as desigualdades se avolumam ainda mais.

Essa realidade ainda é um complicador na condução das aulas durante a pandemia. Segundo o Departamento de Tecnologias Educacionais da Universidade Federal Rural de Pernambuco - UFRPE, em parceria com o Núcleo de Tecnologias 
em Inovações Educacionais do Município de Feira Nova- PE (NTIE), $2 / 3$ dos professores entrevistados afirmam que não dominam com propriedade as plataformas de ensino digitais.

4. Engajamento das Famílias - outro ponto considerado como uma barreira durante a suspensão das aulas pela pandemia, é a ausência de engajamento das famílias no que se refere ao apoio as atividades escolares. Porém, antes de tecer mais comentários sobre esse engajamento, se faz necessário pontuar as possíveis razões pelas quais isso não ocorra a contento.

É necessário que se compreenda que nem toda família tem um teto digno para habitar, existem alguns que nem teto tem, com isso, as estruturas para dá apoio aos filhos que são estudantes sejam limitadas ou até mesmo inexistam. O IBGE em pesquisa realizada em pareceria com a Fundação Getúlio Vargas aponta que o déficit de moradias cresceu 7\% em apenas dez anos, de 2007 a 2017 , tendo atingido 7,78 milhões de unidades habitacionais em 2017, (IBGE, 2017). Há de se considerar também que os pais/responsáveis por esses estudantes não dominem as tecnologias da informação e que não tenham formação suficiente para ajudar na execução das tarefas.

Pode ser pontuado ainda que os pais/responsáveis sejam pessoas que componha a equipe de enfrentamento direta a COVID-ı ou trabalhem em funções que dêem sustentação ao funcionamento das demais pessoas, como indústria de alimentos, EPIs, petróleo, transportes, segurança, etc., ou seja, serviços que não podem parar durante a pandemia e por isso tem um tempo reduzido para acompanhar a enxurrada de atividades recebidas pelo filho.

Segundo Boaventura de Souza Santos (2020), essa pandemia tem sido mais "cruel" com um grupo específico de pessoas (mulheres, negros, imigrantes, indígenas, periféricos, idosos, trabalhadores autônomos, trabalhadores informais, transgêneros, etc.) São justamente nesse grupo onde se encontram as maiores dificuldades na condução das atividades remotas.

O que foi posto até o momento em relação aos problemas enfrentados para conseguir ofertar as aulas nesse contexto de pandemia, no que se refere às questões educacionais, expõe feridas preocupantes. 
Se por um lado se percebe que nem mesmos os países mais desenvolvidos e tecnológicos, conseguiram administrar essa crise de maneira satisfatória na área educacional, mesmo que os prejuízos tenham sido mitigados pelo fato de poder se montar uma rede que agreguem profissionais, alunos e famílias, os resultados dessa rede têm dado respostas aos anseios da sociedade, ainda que aquém do desejado. Some-se a isso ainda o estado de providência social que ancora essas famílias nos países mais ricos e desenvolvidos.

Em oposição a isso, os países que não tem uma cultura de investimento em estrutura e formação na área da educação, enquanto política pública, as sequelas dessa pandemia serão ainda maiores, em certos casos irreversíveis. Estima-se que no Brasil o número de alunos que podem se evadir da escola para ajudar na complementação da renda das famílias nesse momento de crise, aumente. Isso ocorre justamente em um período que se notava uma redução gradativa na taxa de abandono escolar entre os jovens de 15 e 17 anos, o que corresponde aos alunos do Ensino Médio no Brasil, conforme se percebe no gráfico a seguir.

Gráfico I - Percentual de Jovens entre is e I7 anos fora da Escola

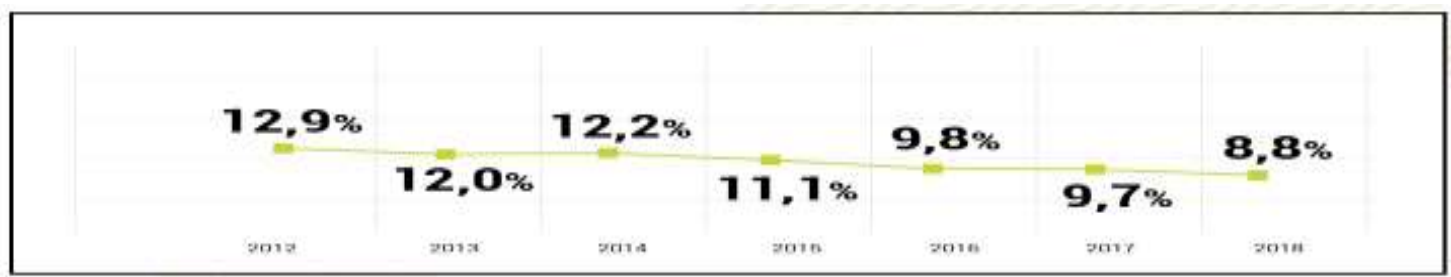

Fonte: Pesquisa Nacional de Amostra Domiciliar - PNAD (IBGE, 2018).

Por fim, a grande discussão do momento são os protocolos sanitários, administrativos e pedagógicos que precisam ser adotados visando o retorno das aulas. O Estado de Pernambuco tem uma população em torno de Io milhões de habitantes e um número aproximado de 2,2 milhões de alunos na educação básica (rede pública e privada), distribuídos em 184 municípios, (MEC, 2018). Considerando ainda a dimensão territorial do Estado, a multiculturalidade (escolas indígenas, quilombolas, escolas do campo, educação para jovens e adultos, etc.) e o nível de desenvolvimento socioeconômico, a construção de um protocolo único é praticamente insustentável. 
Porém, pautado nas experiências já vivenciadas em alguns países europeus, em especial na França, que após a flexibilização de retorno das aulas, pelo menos 70 escolas tiveram que voltar a ser fechadas, por causa do aumento do número de contaminados, as autoridades governamentais estão sendo cautelosos quanto à hora adequada de autorizar o retorno das aulas no Estado. Apesar da pressão por parte das organizações privadas e de alguns setores da sociedade, para a retomada o quanto antes das atividades escolares, a condução do processo tem respeitado os protocolos recomendados pela OMS e autoridades sanitárias locais.

Somado a isso, várias entidades de classe, entre elas o Conselho Nacional de Educação - CNE, o Conselho Nacional de Secretários Estaduais de Educação CONSED, a Confederação Nacional dos Trabalhadores em Educação - CNTE, a União Nacional dos Dirigentes Municipais de Educação - UNDIME, a União Nacional dos Estudantes - UNE, o Conselho Federal de Pediatria, - CFP, entre outros, têm se debruçados no intuito de construir documentos norteadores, que apontem caminhos e possibilidades que garantam um retorno seguro das aulas. Esses documentos abordam orientações sanitárias em parcerias com órgãos da área da saúde, incluindo orientações administrativas, jurídicas e financeiras e principalmente documentos de natureza pedagógicas e curriculares.

Há ainda entidades baseadas em estudos científicos e pautadas nas experiências já vivenciadas pelos países que iniciaram suas flexibilizações, recomendando o não retorno às aulas, até que exista uma vacina. Pesquisadores do Setor de Administração e Planejamento da Universidade de Granada, na Espanha, e do Departamento de Estatística da Universidade de Federal Pernambuco, no Brasil, são categóricos em afirmar que o retorno das aulas nesse momento é uma decisão precipitada e que coloca em risco à saúde dos alunos, profissionais e familiares, uma vez que a taxa de contaminação ocorre de forma exponencial. Afirmam os pesquisadores, que em apenas dois dias de aulas, uma turma com vinte alunos, são capazes de contaminar oitocentas e oito diferentes pessoas. (UFPE, 2020).

Após um ano do início da pandemia, as aulas nas Redes Públicas Municipais de Pernambuco ainda não retornaram de forma presencial. A modalidade do Ensino Médio da Rede Estadual, bem como todas as modalidades da Rede Privada, tiveram 
autorização de retorno desde outubro de 2020, porém, com aumento de casos e mortes em decorrência da segunda onda do coronavírus, foram mais uma vez suspensas, através do Decreto do Governo do Estado de Pernambuco, no 50.433, de 15 de março de 202I.

\section{CONCLUSÃO}

O advento do surgimento da COVID-19, inicialmente na China, mas posteriormente se espalhando por todo o planeta, levando a Organização Mundial de Saúde a declarar que a doença passou a ter status de pandemia, obrigou os países a adotarem medidas até então não usuais na história recente da humanidade.

O negacionismo, a resistência e em certos casos o retardo em adotar as medidas cabíveis, por partes de alguns líderes mundiais, em reconhecer a gravidade da situação, permitiu que o vírus ganhasse fôlego e que dezenas de milhares de vidas fossem ceifadas e tantas outras contaminadas, mostra o quanto tênue é a linha que separa os estadistas, dos que ainda respiram ares de regimes totalitários.

O tamanho do impacto e do estrago provocado pelo novo coronavírus (sanitário, social, econômico, cultural, etc.), expôs que o neoliberalismo, através da ideia do Estado Mínimo se mostra fragilizado, sintomas disso vem ocorrendo desde a crise de 2008, e que o Estado através do modelo de Keynes mais uma vez tem sido o meio adotado para "salvar" inclusive aqueles que pregam o oposto.

Percebe-se ainda que apesar de todo o avanço tecnológico nas diversas áreas, o advento de uma pandemia expõe feridas sérias em vários segmentos da sociedade, incluindo entre elas a educação, um dos setores mais atingidos neste momento. Isso se constata ao ver que as respostas apresentadas não atendem as reais necessidades da grande maioria dos alunos, mesmos aqueles que residem em países considerados desenvolvidos.

Por fim, espera-se que as lições vividas nesse momento sirvam de reflexões, para que a humanidade reveja suas práticas e olhe o planeta como um espaço coletivo, único e finito, mas ainda assim, se usado com racionalidade, totalmente sustentável. 


\section{BIBLIOGRAFIA}

A BÍBLIA SAGRADA: Trad. de João Ferreira de Almeida. 5oa impressão, Rio de Janeiro, Imprensa Bíblica Brasileira, 1993.

BRASIL: Instituto Brasileiro de Geografia e Estatística- IBGE. https://www.ibge.gov.br/estatisticas/sociais/habitacao.html Acesso em $02 / 07 / 2020$.

: Instituto Brasileiro de Geografia e Estatística- IBGE/ PNAD.

https://www.ibge.gov.br/estatisticas/sociais/educacao.html Acesso em 02/o7/2020.

: Ministério da Educação e Cultura. Censo Escolar 2018.

https://www.gov.br/mec/pt-br Acesso em 03/o7/2020.

IISUE (2020): Educación y pandemia. Una visión acadêmica. México, UNAM, 〈http://www.iisue.unam.iisue/covid/educacion-y-pandemia〉, consultado el 25 de mayo, 2020.

INEGI (2018a): "Encuesta Nacional sobre Disponibilidad y Uso de Tecnologías de la Información en los Hogares 2018", México, 〈https://www.inegi.org.mx/programas>, consultado el 30 de abril, 2020.

OCDE (2015): "Se necesita un nuevo enfoque para materializar el potencial de la tecnología en las escuelas", septiembre, 〈https://www.oecd.org/centrodemexico/ medios/se-necesita-un-nuevo-enfoque-para-materializar-el-potencial-de-latecnologia-en-las-escuelas. htm>, consultado el 7 de mayo, 2020.

LOPES, O. C.: A Medicina no Tempo. São Paulo, Edusp/Melhoramentos, I969.

REZENDE, JM.: À sombra do plátano: crônicas de história da medicina [online]. São Paulo: Editora Unifesp, 2009. As grandes epidemias da história. pp. 73-82. ISBN 978-85-61673-63-5. Available from SciELO Books .

SANTOS. B. S.: A Cruel Pedagogia do Vírus. Ed. Boi Tempo, São Paulo, 2020.

UIT (2017): “Development Index", <https://www.itu.int/net4/ITU$\mathrm{D} / \mathrm{idi} / 2017 /$ indextml\#idizorjbyregion-tab>, consultado el 30 de abril, 2020.

Pesquisado na Internet.: https://super.abril.com.br/historia/II-de-setembro-o-queveio-depois/ Acesso em 26/o6/2020

https://exame.com/economia/ha-1o-anos-crise-financeira-de-2008-arrasava-aeconomia-mundial/Acesso em 26/o6/2020

https://www.uffs.edu.br/campi/erechim/noticias/artigo-as-pandemias-na-historia Acesso em 29/o6/2020 
https://revistagalileu.globo.com/Ciencia/Saude/noticia/2020/03/conheca-5maiores-pandemias-da-historia.html Acesso em 29/o6/2020

https://www.medicina.ulisboa.pt/newsfmul-artigo/99/epidemias-e-pandemias-nahistoria-da-humanidade Acesso em 29/06/2020

http://www.invivo.fiocruz.br/cgi/cgilua.exe/sys/start.htm?infoid=815\&sid=7 Acesso em 29/o6 